expenditure of some $£ 500,000$, and annual expenditure on acquisitions of at least $£ 37,500$.

Coming so soon after the memorandum from the librarians of the new universities, this independent, but authoritative, endorsement of the bulk of the argument of that memorandum is impressive. It demonstrates convincingly that what we should be looking for is not economy but an assurance that the provision being made for the academic libraries, whether in the new universities, the established institutions, or in the colleges of technology, is sufficiently generous, alike in respect of books, of periodicals, of accommodation and of staff and their terms of service. The range and scope of the questions put to the Library Association by the Committee on Libraries at least suggest that that Committee is now aware of the magnitude of the issues. The advice it has already received should go far to ensure that an imaginative report is forthcoming, with recommendations meeting the situation, provided that the Committee is sufficiently resolute to grasp the opportunities confronting it.

\section{MAN'S DEVELOPING DILEMMA}

Automation and the Future of Man

By S. Demczynski. Pp. 238. (London: George Allon and Unwin, Ltd., 1964.) $32 s$.

THE author of this book is obviously a well-read and highly intelligent man. His experience as a prisoner in a forced labour camp behind the Iron Curtain and his present occupation with automatic machinery and data processing equipment have caused him to ponder deeply on the problem of the moral nature of man. For, if it were true that future developments in cybernetics would reduce almost to nothing the distinction between the functioning of man and of machines and if, as seems likely by the end of the century, life were to be produced in a test-tube, does this not spell the beginning of the end of man's distinctive position in the world? Moreover, will not the increasing tendency, especially in tho social sciences, to interpret human behaviour in deterministic terms destroy the basis for any moral code ?

It is a pity that the author should have chosen such a cliché for a title and that ho should have tried to cover so vast a field. The result is inevitably patchy. By far the best chapters are in the second part in which he considers the problems of free-will and determinism and of the relationship between mind and brain in the light of modern scientific knowledge.

Mr. Demczynski's solution to the dilemma posed by our increasing knowledge of the physiological processes of thought is the concept of increasing complexity of the system. In a similar way as matter is now known to be transmutable into energy, so matter when connected intimately with the mind tends towards the formation of extremely complex systems and so changes its own nature. Such complex systems exhibit freedom of choice and therefore make value dişcussions meaningful. If this eoncept is to be accepted it has to overcome two obstacles which the author faces, but, not surprisingly, does not resolve. The first is that it is in contradiction to the second law of thermodynamics by which entropy increases. His only answer to this is to suggest that there exists an opposing tendency in Nature corresponding to the Freudian concept of the will to live in contrast to the will to destroy and die. But this is a metaphysical concept which still leaves us seeking for a first cause for which the non-religous philosophers of the world have been searching through the centuries. The second obstacle is the problem posed by the increasing complexity of machines themselves. Here his solution is itself contra- dictory, for while he admits that machines may have the potential possibilities of men he believes that in some way this admission will enable the capacities of men to be clearly seen as superior. The comparison of man as he is with the best machines now available can only raise the status of the former.

These ideas are still a long way from the possibility of scientific investigation and they must remain a matter of belief and related as such to personal values. The author is a convinced humanist. To defy rationality, he writes, is to condemn in the end the whole effort of human civilization. Attracted to existentialism because of its support for the individual's freedom of will, he nevertheless realizes that a socially useful ethic cannot be built on the basis of complete subjectivity.

In the end his logical thinking joins his generous emotions in producing a dislike of a society the only motive of which is economic gain. This leads him to socialism and the need for planning.

Unfortunately, just when his industrial experience and analytical mind could have made a real contribution to the practical problems of society in an age of rapid technological change, the argument becomes discursive and leads to some rather unthought-out conclusions: for example, that government should be in the hands of an educated and socially conscious oligarchy-meaning the professional middle class.

Although he appears to believe that there is nothing to be hoped for between total disarmament and total destruction he dismisses the "few hundred thousand deaths due to increased loukæmia" caused by fall-out from nuclear tests, with very little argument, as necessary for the preservation of national independence and the Western way of living. All this is much beneath the level of the rest of this interesting attempt to face some of the philosophical problems raised by man's excessive ingenuity.

Austen Albu

\section{SOCIAL CHANGE}

\section{On the Theory of Social Change: How Economic Growth Begins}

By Prof. Everett E. Hagen. (Study from the Center for International Studies, Massachusetts Institute of Technology.) Pp. xvii + 557. (London: Tavistock Publications (1959), Ltd., 1964.) $63 s$.

CHE sub-title of this book is: "How Economic Growth Begins", and the author is concerned with a hypothesis about the changes that take place as a 'traditional' society moves towards modern entrepreneurial methods. What factors promote and what factors impede such a process?

So far as impediments are concerned, Prof. Hagen dismisses the familiar economic arguments-inability to save, lack of capital, lack of 'know-how', lack of markets and inadequate transportation. His arguments are compelling and he adduces evidence to show that economic growth has in fact taken place in the absence of these advantages. Of course the presence of adequate markets, adequate transport systems, capital and the rest of it are a help, but if they are provided from outside sources they will be useless unless the inhabitants for whose use they are intended have the right attitude of mind. His argument is similar to that of McClelland, who has put forward the view that material aid to underdeveloped countries is far less important than the inculcation of the 'achievement motive?.

Prof. Hagen's thesis involves a more complicated analysis. Underdeveloped countries have a 'traditional' culturs, which is passed on from generation to generation by their child-rearing practices. This is treated in some detail; the upshot is that children are brought up in an 'authoritarian' atmosphere, in which they learn the rules 